\title{
THE INFLUENCE ON ATMOSPHERIC COMPOSITION OF VOLCANIC ERUPTIONS AS DERIVED FROM ICE-CORE ANALYSIS
}

\author{
by
}

\author{
C.U. Hammer
}

(Geophysical Isotope Laboratory, University of Copenhagen, Haraldsgade 6, DK-2200 Copenhagen, Denmark)

\section{ABSTRACT}

Polar ice cores offer datable past snow deposits in the form of annual ice layers, which reflect the past atmospheric composition. Trace substances in the cores are related to the past mid-tropospheric impurity load, this being due to the vast extent of the polar ice sheets (or ice caps), their surface elevations and remoteness from most aerosol sources. Volcanic eruptions add to the rather low background impurity load via their eruptive products. This paper concentrates on the widespread influence on atmospheric impurity loads caused by the acid gas products from volcanic eruptions. In particular the following subjects are discussed: acid volcanic signals in ice cores, latitude of eruptions as derived by ice-core analysis, inter-hemispheric dating of the two polar ice sheets by equatorial eruptions, volcanic deposits in ice cores during the last glacial period and climatic implications.

\section{INTRODUCTION}

Polar ice cores offer a means of dating past snow deposits in the form of annual ice layers, which reflect past atmospheric composition. Trace substances in the cores are related to the past mid-tropospheric impurity load, this being due to the vast extent of the polar ice sheets (or ice caps), their surface elevations and remoteness from most aerosol sources.

By means of their eruptive products volcanic eruptions add to the rather low background impurity load, which in turn is reflected in the concentration of trace substances in the snow falling onto the ice sheet. Several well-known historical eruptions have marked the polar ice sheets with their widespread acid gas products (Hammer 1977[b], Hammer and others 1980, Delmas and Boutron 1980, Herron 1982, Koerner and Fisher 1982).

How far back in time the polar ice sheets can be used as indicators of widespread atmospheric impurity load depends on their flow history. From theoretical considerations and results obtained from deep cores it can be inferred that continuous records representing the pas few hundred thousand years should be obtainable at carefully selected sites. The actual time limit can only be determined by drilling at the most favourable locations, and it may vary from a few hundred thousand years to perhaps most of the Quaternary era.

The value of the ice sheets as indicators of the influence of volcanism (or other sources of atmospheric trace substances) on the chemical composition of the atmosphere, over short- or long-time intervals, does, however, depend on our ability to relate concentrations in the deposited snow at a particular location to the local atmospheric concentrations. Very little happens to the concentrations when the snow is transformed into ice, at least in areas of high annual snow deposition (i.e. more than approximately $10 \mathrm{~g}$ of water $\mathrm{cm}^{-2} \mathrm{a}^{-1}$ ). Glaciological and meteorological phenomena can cause a considerable noise in records by their influence on the top $\sim 20 \mathrm{~cm}$ of snow. This is not discussed in this paper. This problem can be solved by having several cores from a location. If such a relation can be established with reasonable accuracy the next step is to relate local atmospheric composition to regional, hemispheric or global conditions. The latter may be quite complicated and each type of source of trace substance must be treated separately.

\section{ICE CONCENTRATION TO AIR CONCENTRATION $\left(\mathrm{C}_{\text {ice }} / \mathrm{C}_{\text {air }}\right)$ \\ Junge (1977) has discussed the conditions under which} the trace substance concentration in precipitation is proportional to that in the precipitating air mass. The conditions he stated are fulfilled for the most central parts of the polar ice sheets.

(a) In-cloud riming

Junge did not discuss the possibility of in-cloud riming and further assumed that nearly all condensation nuclei were used up in the precipitation event. If in-cloud riming is effective during precipitation, this could have a serious effect on the relation between ice and air concentration of trace substances $\left(\mathrm{C}_{\mathrm{ice}} / \mathrm{C}_{\mathrm{air}}\right) \quad(\mathrm{L} \quad \mathrm{A}$ Barrie personal communication). Riming enrichments of trace substance concentrations of up to 50 times have been observed in continental precipitation. If in-cloud riming was a frequent and seasonally dependent phenomenon over the polar ice sheets, one would expect, a priori, a very strong seasonal variation as well as very abrupt changes in the impurity concentrations of the various snowfalls.

Average yearly peak values of dust in ice cores (Hammer 1977[a]), sulphate (Herron and Langway 1985), sea salt ( $\mathrm{R} C$ Finkel and others personal communication) and nitrate (Risbo and others 1981) occur in different seasons which probably relate to natural air concentration changes, rather than to riming. Further, if data from Greenland ice cores are used to infer mid-tropospheric aerosol load (in periods of little volcanism) the estimate is a few million tonnes, i.e. close to estimates based on direct or indirect atmospheric measurements (Junge 1974).

In-cloud riming is only possible if a large number of small supercooled water droplets coexist with the precipitating snow crystals. This situation is not very likely in the centre of ice sheets during the winter (apart from south Greenland). Apparently riming contributes little to the annual average values of impurity concentrations in the snow deposits, probably because of the clean-air regime over the ice sheets, but more research is needed on this important subject.

It is not so much the occurrence of riming, which is important for the interpretation of ice-core data, as how much its contribution to annual snow concentrations varies from year to year and/or over different climatic periods. A guideline may be obtained by comparing the seasonal deposition of volcanic products from several well-known large eruptions which show a deposition pattern from north to south Greenland which is not easily explained by riming (Hammer 1984). In fact, the deposition pattern is much better explained by the general spreading of the volcanic aerosol in the atmosphere.

(b) Individual precipitations $\left(\mathrm{C}_{\mathrm{ice}} / \mathrm{C}_{\mathrm{air}}\right)$

Ice-to-air concentrations are generally influenced by individual snowfall characteristics. The effect can only be described in a statistical manner because nearly all data obtained on individual snow- or rainfalls are derived from 
averages over a whole precipitation event (Barrie personal communication).

In order to correct for the effect of individual precipitations a number of assumptions must be made. It should, however, be emphasized that the correction for most polar ice cores will only be of the order of a factor of from 0.6 to 3 , the largest correction being necessary for low accumulation areas (for an individual event, not for yearly averages!).

It is assumed that (1) snow and rain scavenging efficiencies are of the same order of magnitude, (2) relations between ice and air concentrations, based on data from outside the polar regions (excluding heavily-polluted areas), can be adapted to polar regions because the fundamental processes in washout are similar (though not identical), and (3) the average individual precipitation for an ice-sheet site is known. If these conditions are fulfilled it is possible to relate concentrations of trace substances in ice, $\mathrm{C}_{\mathrm{ice}}$, and air $\mathrm{C}_{\mathrm{air}}$ (as a first order approximation):

$$
\mathrm{C}_{\mathrm{ice}} / \mathrm{C}_{\mathrm{air}}=\mathrm{kPP}_{\mathrm{i}}^{-0.3}
$$

(Junge 1963: 311-315). Choosing a situation, where the air concentrations at two different polar ice-sheet sites are equal, but having different average individual precipitations $\mathrm{p}_{1}$ and $\mathrm{p}_{2}$, we have for the corresponding ice concentrations:

$$
\mathrm{C}_{1} / \mathrm{C}_{2}=\left(\mathrm{P}_{1} / \mathrm{P}_{2}\right)^{-0.3} \text {. }
$$

Further, we have for the average individual precipitation $\mathrm{p}_{\mathrm{i}}$ :

$$
\mathrm{A}=\mathrm{P}_{\mathrm{i}} \mathrm{N},
$$

where $\mathrm{A}$ is the yearly precipitation and $\mathrm{N}$ the number of individual precipitations per year.

In Figure $1 \mathrm{P}_{i}$ has been plotted against the value of $\mathrm{A}$ for various stations on the Antarctic and Greenland ice sheets. The values of $\mathrm{P}_{\mathrm{i}}$ have been obtained from a number of pit studies and from the interpretation of continuous time series of dust and acidity along ice cores $(1 \mathrm{~mm}$ resolution). The data from areas of low precipitation (such as the South Pole), i.e. less than $10 \mathrm{~cm} \mathrm{H}_{2} \mathrm{O} \mathrm{a}^{-1}$, had to be partly guessed. The continuous profiles showed that blowing winds had almost obliterated the individual snowfall signature. However, it is reasonable that as A approaches zero so should $\mathrm{P}_{\mathrm{i}}$. This is not completely true due to the possibility of evaporation and drift accumulation which may be important for areas of low precipitation. In any case, areas of low precipitation are complicated and the phrase annual accumulation of snow is more appropriate so that Figure 1 is, therefore, only indicative for such regions.

From Figure 1 it can be seen that there seems to be a fairly simple linear relation between $A$ and $P_{i}$ for high precipitations. Evidently, the areas of low precipitation are isolated from meteorological phenomena associated with significant amounts of precipitation in the general circulation. High elevations, remoteness of water vapour sources and protection by geographical features all play a role in determining the relation between $\mathrm{P}_{\mathrm{i}}$ and $\mathrm{A}$; the linear relation between the chosen stations must be accidental. It should, however, be noted that all stations are far from the ice margin and give a fairly good coverage of the interior of the Greenland ice sheet. There are only two data sets from West Antarctica, but they are at least representative for large areas. The low-accumulation area of East Antarctica is only formally represented by the stipulated line in Figure 1.

Figure 2 shows the relation between $A$ and $\left(C_{i c e} / C_{a i r}\right) / k$ for a constant air concentration as calculated by Equation (1) and based on the observed values of $\mathrm{P}_{\mathrm{i}}$. Three important qualitative conclusions can be derived from Figure 2, even though Equation (1) is only a first approximation to the real conditions: (1) ice cores from areas of high precipitation reflect the local air concentrations of trace substances with less influence from the annual individual precipitation characteristics, (2) areas of low accumulation must be carefully scrutinized before air

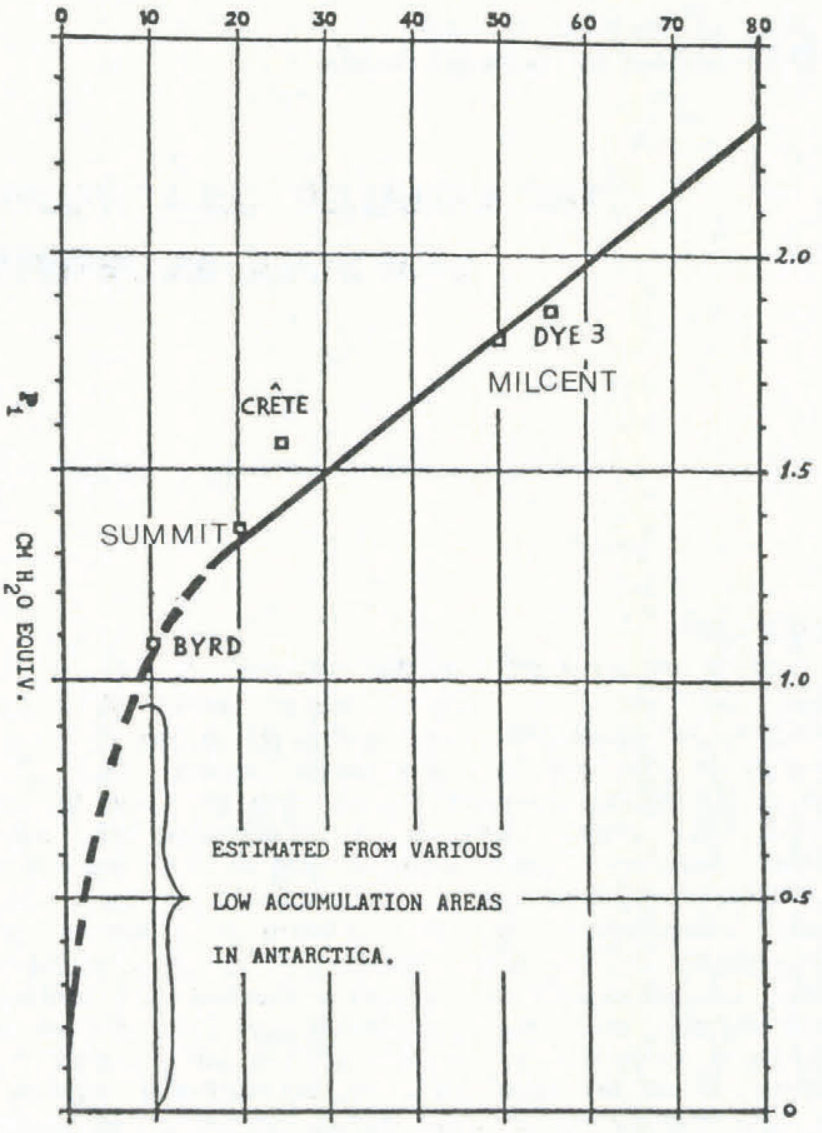

A $\mathrm{CM} \mathrm{H}_{2} \mathrm{O}$ EOUIV. PR. YEAR

Fig.1. Average individual precipitation at various polar ice-sheet sites, as derived from continuous ice core or snow pit measurements in the field.

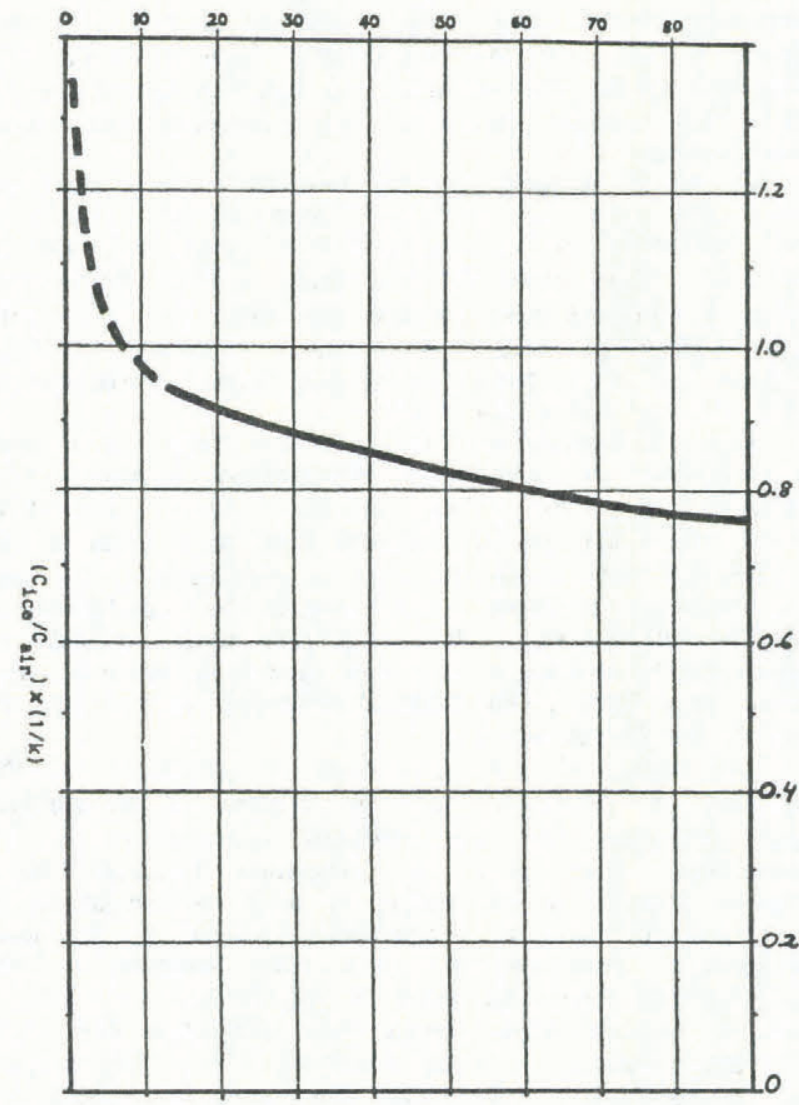

A $\mathrm{CM} \mathrm{H}_{2} \mathrm{O}$ EOUIV. PR. YEAR

Fig.2. The relation between local air concentrations and ice concentration as a function of annual precipitation (accumulation) at the site in question. 
and ice concentrations can be related in a quantitative way, and (3) changes in annual precipitation due to climatic changes have only little influence on the relation between local air to local ice concentration, if the region is an area of high precipitation.

The latter point has important consequences for the interpretation of ice-core data on trace substances covering glacial times when precipitation on the Greenland and Antarctic ice sheets was probably 2 to 5 times lower than today (Hammer and others 1978, Raisbeck and others 1981, Hammer and others 1985).

During such times of smaller precipitation in the polar regions there is generally less washout of aerosols, which in turn results in higher air concentrations and a new washout equilibrium (disregarding other meteorological changes and changes in source regions). This increase in air (ice) concentration is not due to a local precipitation effect, but caused by regional or hemispheric changes. It is possible that the latter are reflected in a local lowering of precipitation but it is not a necessity, and it may be quantitatively different from the average behaviour.

I have treated the relation between $C_{i c e}$ and $C_{\text {air }}$ in some detail, because it is essential to be aware of this relation before one undertakes a comparison of ice-core data from Antarctica and Greenland, or a comparison of ice-age data to Holocene data, or a comparison of, for example, Holocene time series of accumulation to the same time series of trace substance concentrations (be it on volcanic acids, sea salts, $\mathrm{Be}^{10}$, etc.).

\section{ATMOSPHERIC SPREADING OF VOLCANIC PRODUCTS}

The spreading of volcanic submicron particles and gases in the upper atmosphere is governed by meteorological conditions which are more stable than the more complicated and noisy lower troposphere. The processes of wet removal in the lower troposphere are both more frequent and effective than in the upper atmosphere. Large tephra fragments usually fall out by gravity before they reach the ice sheets (see, however, Gow and Williamson 1971, Kyle and Jezek 1978, Kyle and others 1981). The acid gas products from volcanoes that are remote from ice sheets only reach the latter if the products avoid the heavy washout which takes place in the low troposphere. Sulphur dioxide may spread further via the low troposphere than the more hydrophilic $\mathrm{HCl}$ and $\mathrm{HF}$, but if the eruption took place for example, far south of Greenland, only insignificant amounts of material transported in the lower troposphere will reach the ice sheet. Eruptions remote from the ice sheets, but taking place in the same latitude zone, may in some cases contribute to the ice-sheet chemistry via gases transported in the lower troposphere.

A fairly large fraction of the volcanic acids, which caused the strongest signals in the Greenland ice cores, must have been transported in the upper atmosphere. In case of an eruption like Tambora 1815, the transport must have been via the stratosphere, but for a lava eruption like Lakigigar 1783, on Iceland, transport in the upper troposphere best explains the acid signal.

In order to judge the magnitude of eruptions, with respect to acid gas production from ice-core studies, it is necessary to rely on indirect evidence or on some average behaviour of the atmospheric transport of the products.

\section{NUCLEAR BOMB TESTS: MAGNITUDES LATITUDES OF ERUPTIONS}

AND

Data from the nuclear bomb tests since 1953 indicate that the transport, spreading and subsequent deposition of upper atmospherically-injected trace substances follow some average pattern. In wide latitude zones the fallout pattern in time does not vary much (but the average concentration does). Significant changes in the pattern are seen when the latitude zones $30^{\circ} \mathrm{N}$ to $90^{\circ} \mathrm{N}, 30^{\circ} \mathrm{N}$ to $30^{\circ} \mathrm{S}$ and $30^{\circ} \mathrm{S}$ to $90^{\circ} \mathrm{S}$ are compared. For several years the radioactive aerosol was mainly caused by a few detonations which made it possible to relate ice concentrations to the magnitude of the detonations. From such data it was possible to relate ice concentration caused by a volcanic eruption to the total injected acid gases from the eruption. It is a prerequisite that the latitude zone of the eruption is known (Hammer
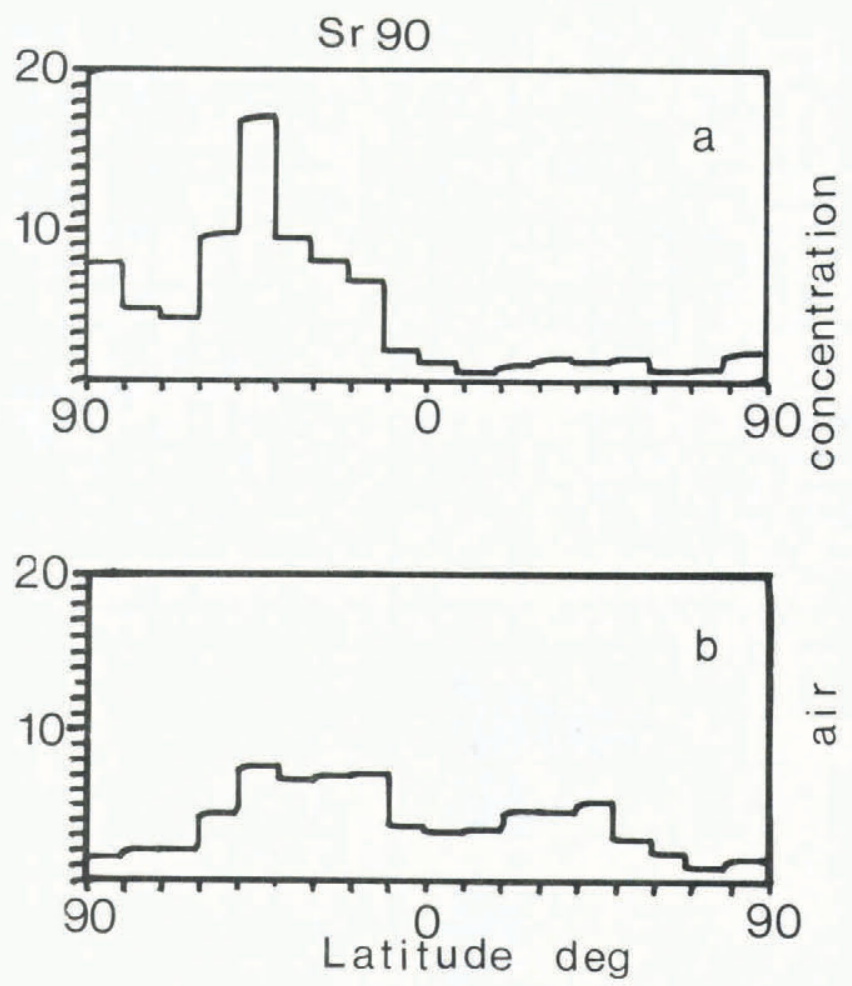

Fig.3. The latitudinal distribution of $\mathrm{Sr}^{90}$ concentration (relative scale) in the precipitating air mass from two nuclear explosions of the same magnitude: (a) detonation in the high Arctic, (b) detonation at the equator (based on data from the report of the United States Atomic Energy Commission Health and Safety Laboratory (1974)) and various polar ice-sheet data.

and others 1981). Such estimates are not ideal, but they are at least based on the measured spread of $\mathrm{Sr}^{90}$.

In Figure 3 relative air concentrations of $\mathrm{Sr}^{90}$ over different latitude zones are shown for two nuclear surface detonations of the same magnitude, one detonated in the high Arctic and one at the equator. The air concentration refers to the air of the precipitating air mass (not surface air) and the distribution pattern to the year following the detonation, except for the values south of the equator for the high Arctic detonation where the fallout could not be resolved from other and later detonations. Figure 3 is based on data from the United States Atomic Energy Commission Health and Safety Laboratory report (1974) and various data from Greenland and Antarctic ice cores.

Even though an explosive volcanic eruption is not a nuclear detonation and $\mathrm{Sr}^{90}$ is not an acid volcanic gas product, estimates of total volcanic acid products based on $\mathrm{Sr}^{90}$ data lead to reasonable results. Estimates of magnitudes of eruptions based on volcanological data and ice cores are in essential agreement (Thorarinsson 1969, Stothers 1984, H Sigurdsson personal communication). The agreement is only within a factor of 2, but that is acceptable, considering that most eruptions used in such a comparison took place before volcanic aerosols were monitored by instruments.

More recently, the data from satellites have greatly increased our knowledge of the atmospheric transport of volcanic products as in the case of the El Chicon 1982 eruption. However, the fission product data offer a direct comparison between magnitudes of material injected and ice-core concentrations. Another important advantage of the fisson product concentrations in ice cores is the pure signal, i.e. the natural background is negligible.

Comparison of eruptive volcanic signals in ice cores from north, south, and central Greenland even suggest that some information on the latitudinal zone of the eruption can be derived (Hammer 1984). A particularly interesting large eruption around AD 1257-58 (though unknown) clearly marked the Greenland and Antarctic ice sheets with high acidity (maximum deposition year in Greenland AD 1259). Hence the eruption must have taken place in the equatorial zone. 
In the absence of any information (indirect or direct) about the location of an eruption, causing a high acidity signal, the estimate of its contribution to the upper atmospheric impurity load will be less accurate. Typically an uncertainty of a factor of 2 to 3 may be expected. An additional source of error arises from the various meteorological conditions which reigned in the months and first few years following the eruptions. In few cases it could cause an error of a factor of 2. For small and moderately large eruptions, polar ice cores can be used to estimate the general contribution to atmospheric chemistry and aerosol load rather than to estimate the contribution from the individual smaller eruptions. For these smaller volcanic events it is not possible to estimate the contribution from various latitude zones. Comparison between well-dated and continuous records from ice cores in

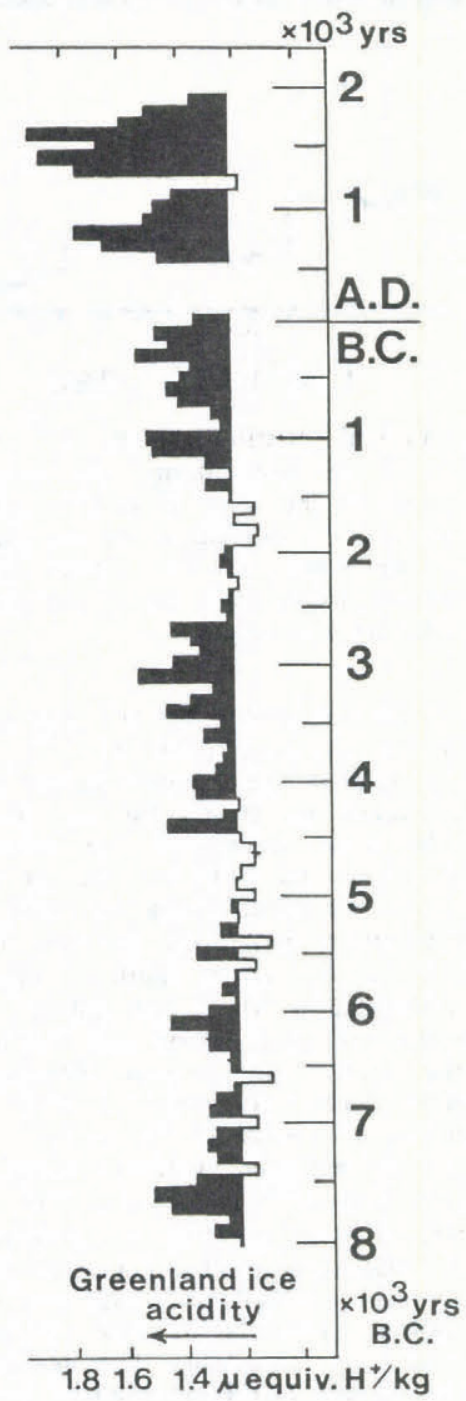

Fig.4. The influence of volcanism on the mid-tropospheric impurity load (given as excess acidity set out in black) over the northern hemisphere, as derived from the Camp Century, Greenland, ice core. The figure is based on ca. 10000 individual measurements, but presented in 100 year mean values. Time scale is in Hammer and others (1978).

both the northern and southern hemisphere may help solve this problem, but changes in ice-core impurity concentrations due to climatic feedback mechanisms also have to be sorted out.

Nothing has been mentioned about the amount and type of material released in a particular type of eruption; this is a problem of volcanology rather than one of tracing the volcanic products from the eruption site to the ice cores.
CHEMICAL COMPOSITION OF VOLCANIC PRODUCTS IN ICE CORES

The bulk chemical composition of the Holocene volcanic aerosol reaching the ice sheets consists of components such as $\mathrm{H}_{2} \mathrm{SO}_{4}, \mathrm{HCl}$ and $\mathrm{HF}$, their neutralized components such as $\left(\mathrm{NH}_{4}\right)_{2} \mathrm{SO}_{4}, \mathrm{NH}_{4} \mathrm{Cl}, \mathrm{NH}_{4} \mathrm{HSO}_{4}, \mathrm{NH}_{4} \mathrm{~F}$, and, to some extent, products of hydrolysis. (As mentioned previously, tephra may contribute in Antarctic ice cores.) The actual chemical composition varied from eruption to eruption, but $\mathrm{H}_{2} \mathrm{SO}_{4}$ was generally an important component.

During the last glacial period the acids were neutralized by alkaline material in the northern hemisphere and the volcanic products are mainly present in the cores as calcium salts (neutralized by calcium-rich carbonates) (Hammer and others 1980, 1985). The Antarctic snow remained acid during this period, because the southern atmosphere was less influenced by ocean-free continental shelves and loess sources.

While the contribution from volcanism to the atmospheric trace substance load (excluding low troposphere) averages some 10 to $15 \%$ over the Holocene period (Fig.4), less is known about the glacial period. During such times the climatic and environmental conditions were quite different from the Holocene and, hence, there is more uncertainty in translating ice concentrations to atmospheric load. Even if we assume that the stratospheric spreading of an eruption cloud did not differ from the present pattern, we will still be left with some problems: (1) how efficient was the transfer from stratosphere to mid-tropospheric precipitating air masses during glacial times? (2) how did the strong winds and different source regions change the non-volcanic background variability as compared to Holocene conditions? (3) how did the probably smaller precipitation in polar regions affect the polar aerosol load?

These are only some of the problems, but recent data on volcanic signals in the Byrd core covering glacial times suggest that the most important correction is associated with the smaller precipitation in the polar regions (Hammer and others in preparation).

For marine- or continental-derived material changes in winds, source regions and precipitation are all important parameters which contribute to ice-core concentrations during glacial times.

\section{VOLCANISM AND CLIMATE}

The climatic implications of volcanism have been widely discussed throughout the last few decades. Apart from the problem of modelling the climatic effects of volcanic aerosols (see, for example, Hunt 1977 and Pollack and others 1976), there is a need to compare palaeoclimatic and palaeovolcanic records. Data from the ice cores can also be used as input data in models, especially when more data on the chemistry becomes available.

Volcanic activity also plays an important role in the geochemical cycle and, even though the polar ice cores only cover a small time period, they do offer a fairly large data library on the frequency, mass and type of widespread volcanic aerosols.

\section{ACKNOWLEDGEMENTS}

I want to thank the organizing committee of the Trent 1984 Symposium and the Royal Society of Canada for making it possible for me to participate in the conference and finishing this paper. Also, I appreciate the help of $\mathrm{R}$ Koerner and D Fisher, Polar Continental Shelf Project, Energy, Mines and Resources Canada, who successfully tricked me into finishing this paper.

\section{REFERENCES}

Delmas R, Boutron C 1980 Are the past variations of the stratospheric sulfate burden recorded in central Antarctic snow and ice layers? Journal of Geophysical Research 85(C10): 5645-5649

Gow A J, Williamson T 1971 Volcanic ash in the Antarctic ice sheet and its possible climatic implications. Earth and Planetary Science Letters 13(1): 210-218 
Hammer C U 1977[a] Dating of Greenland ice cores by microparticle concentration analysis. International Association of Hydrological Sciences Publication 118 (General Assembly of Grenoble 1975 - Isotopes and Impurities in Snow and Ice): 297-301

Hammer C U 1977[b] Past volcanism revealed by Greenland ice sheet impurities. Nature 270(5637): 482-486

Hammer C U 1984 Traces of Icelandic eruptions in the Greenland ice sheet. Jökull 34: 51-65

Hammer C U, Clausen H B, Dansgaard W, Gundestrup N, Johnsen S J, Reeh N 1978 Dating of Greenland ice cores by flow models, isotopes, volcanic debris and continental dust. Journal of Glaciology 20(82): 3-26

Hammer C U, Clausen H B, Dansgaard W 1980 Greenland ice sheet evidence of post-glacial volcanism and its climatic impact. Nature 288(5788): 230-235

Hammer C U, Clausen H B, Dansgaard W 1981 Past volcanism and climate revealed by Greenland ice cores. Journal of Volcanology and Geothermal Research 11(1): 3-10

Hammer C U, Clausen H B, Langway C C Jr 1985 The Byrd ice core: continuous acidity measurements and solid electrical conductivity measurements. Annals of Glaciology 7: 214

Hammer C U, Clausen H B, Dansgaard W, Neftel A, Kristinsdottir P, Johnson E 1985 Continuous impurity analysis along the Dye 3 deep core. In Langway C C Jr, Oeschger H, Dansgaard W (eds) Greenland ice core: geophysics, geochemistry, and the environment. Washington, DC, American Geophysical Union: 90-94 (Geophysical Monograph 33)

Herron M M 1982 Impurity sources of $\mathrm{F}^{-}, \mathrm{Cl}^{-}, \mathrm{NO}_{3}^{-}$and $\mathrm{SO}_{4}{ }^{2-}$ in Greenland and Antarctic precipitation. Journal of Geophysical Research 87(C4): 3052-3060

Herron M M, Langway C C Jr 1985 Chloride, nitrate and sulfate in the Dye 3 and Camp Century, Greenland ice cores. In Langway C C Jr, Oeschger $\mathrm{H}$, Dansgaard W (eds) Greenland ice core: geophysics, geochemistry, and the environment. Washington, DC, American Geophysical Union: 77-84 (Geophysical Monograph 33)

Hunt B G 1977 A simulation of the possible consequences of a volcanic eruption on the general circulation of the atmosphere. Monthly Weather Review 105(3): 247-260

Junge C E 1977 Processes responsible for the trace content in precipitation. International Association of Hydrological Sciences Publication 118 (General Assembly of Grenoble 1975 - Isotopes and Impurities in Snow and Ice): 63-77

Junge C E 1963 Air chemistry and radioactivity. Vol 4. New York, Academic Press

Junge C E 1974 Important problems of global pollution. In: Proceedings of the international conference on structure, composition and general circulation of the upper and lower atmospheres and possible anthropogenic perturbations (January 14-25, 1974) ... held at the University of Melbourne, Melbourne, Australia. Vol 1. Toronto, 1974: 1-16

Koerner R M, Fisher D 1982 Acid snow in the Canadian high Arctic. Nature 295(5845): 137-140

Kyle P R, Jezek P A 1978 Composition of the tephra layers from the Byrd station ice core, Antarctica. Journal of Volcanology and Geothermal Research 4: 225-232

Kyle P R, Jezek P A, Mosley-Thompson E, Thompson L G 1981 Tephra layers in the Byrd station ice core and the Dome-C ice core, Antarctica and their climatic importance. Journal of Volcanology and Geothermal Research 11(1): 29-39

Pollack J B, Toon O B, Sagan C, Summers A, Baldwin B, Van Camp W 1976 Volcanic explosions and climatic change: a theoretical assessment. Journal of Geophysical Research 81(6): 1071-1083

Raisbeck G M and 6 others 1981 Cosmogenic ${ }^{10} \mathrm{Be}$ concentrations in Antarctic ice during the past 30,000 years. Nature 292(5826): 825-826

Risbo T, Clausen H B, Rasmussen K L 1981 Supernovae and nitrate in the Greenland ice sheet. Nature 294(5842): 637-639

Stothers R B 1984 The Great Tambora eruption in 1815 and its aftermath. Science 224(4654): 1191-1198

Thorarinsson S 1969 The Lakagigar eruption of 1783. Bulletin Volcanologique 33(3): 910-929
United States Atomic Energy Commission. Health and Safety Laboratory 1974. Appendix. Fallout program; quarterly summary report, January 1, 1974. New York, US Atomic Energy Commission (HASL - 278) 